\title{
The AKT inhibitor MK2206 suppresses airway inflammation and the pro-remodeling pathway in a TDI-induced asthma mouse model
}

\author{
HAIYAN CUI ${ }^{1,2}$, YUANXIONG CHENG ${ }^{2}$, YI HE $^{3}$, WEIYING CHENG ${ }^{2}$, WENQU ZHAO ${ }^{1}$, \\ HAIJIN ZHAO ${ }^{1}$, FIONA H. ZHOU ${ }^{4}$, LIPING WANG ${ }^{4}$, JIANGHUI DONG ${ }^{4}$ and SHAOXI CAI ${ }^{1}$
}

\author{
${ }^{1}$ Department of Respiratory and Critical Care Medicine, Chronic Airway Disease Laboratory, Nanfang Hospital of \\ Southern Medical University, Guangzhou, Guangdong 510000; Departments of ${ }^{2}$ Respiratory and Critical Care Medicine \\ and ${ }^{3}$ Immunology Medicine, The Third Affiliated Hospital of Southern Medical University, Guangzhou, \\ Guangdong 510630, P.R. China; ${ }^{4}$ UniSA Clinical and Health Sciences, UniSA Cancer Research Institute, \\ University of South Australia, Adelaide, South Australia 5001, Australia
}

Received April 10, 2020; Accepted July 14, 2020

DOI: $10.3892 / \mathrm{mmr} .2020 .11450$

\begin{abstract}
The cellular and molecular mechanisms via which MK2206, an AKT inhibitor, prevents the activation of AKT in toluene diisocyanate (TDI)-induced asthma remain unclear. Thus, the present study aimed to evaluate the potential effects of MK2206 on airway AKT activation, inflammation and remodeling in a TDI-induced mouse model of asthma. A total of $24 \mathrm{BALB} / \mathrm{c}$ mice were selected and randomly divided into untreated (AOO), asthma (TDI), MK2206 (TDI + MK2206), and dexamethasone (TDI + DEX) groups. Phosphorylated AKT (p-AKT), total AKT, airway remodeling indices, $\alpha$-smooth muscle actin ( $\alpha$-SMA) and collagen I levels in pulmonary tissue were measured using western blotting. Airway inflammation factors, including interleukin (IL)-4, -5, -6 , and -13 in bronchoalveolar lavage fluid (BALF) and $\operatorname{IgE}$
\end{abstract}

Correspondence to: Dr Jianghui Dong, UniSA Clinical and Health Sciences, UniSA Cancer Research Institute, University of South Australia, HB Building, Corner North Terrace, Morphett Street, Adelaide, South Australia 5001, Australia

E-mail: jianghui.dong@mymail.unisa.edu.au

Professor Shaoxi Cai, Department of Respiratory and Critical Care Medicine, Chronic Airway Disease Laboratory, Nanfang Hospital of Southern Medical University, 1838 North Guangzhou Avenue, Guangzhou, Guangdong 510000, P.R. China

E-mail: caishaox@fimmu.com

Abbreviations: $\alpha$-SMA, $\alpha$-smooth muscle actin; AHR, airway hyperresponsiveness; ASM, airway smooth muscle; PAS, periodic acid-Schiff; BALF, bronchoalveolar lavage fluid; HMGB1, high mobility group box 1; IL, interleukin; p-AKT, phosphorylated AKT; TDI, toluene diisocyanate; WB, western blotting; DEX, dexamethasone

Key words: MK2206, TDI-induced asthma, airway inflammation, airway remodeling, AKT in serum, were determined using ELISA. Additionally, the airway hyperresponsiveness (AHR) and pulmonary pathology of all groups were evaluated. The results of the present study demonstrated that p-AKT levels in lung protein lysate were upregulated, and neutrophil, eosinophil and lymphocyte counts were increased in the lungs obtained from the asthma group compared with the AOO group. Both MK2206 and DEX treatment in TDI-induced mice resulted not only in the attenuation of AKT phosphorylation, but also reductions in neutrophil, eosinophil and lymphocyte counts in the lungs of mice in the asthma group. Consistently, increases in the levels of the inflammatory cytokines IL-4, $-5,-6$ and -13 analyzed in BALF, and serum IgE in the TDI group were demonstrated to be attenuated in the TDI + MK2206 and TDI + DEX groups. Furthermore, $\alpha$-SMA and AHR were significantly attenuated in the TDI + MK2206 group compared with the TDI group. These results revealed that MK2206 not only inhibited AKT activation, but also served a role in downregulating airway inflammation and airway remodeling in chemical-induced asthma. Therefore, the findings of the present study may provide important insight into further combination therapy.

\section{Introduction}

Bronchial asthma is a heterogeneous disease characterized by chronic airway inflammation (1). There are $\sim 235$ million individuals suffering from asthma worldwide (2). Toluene diisocyanate (TDI), a chemical intermediate used in the manufacture of several synthetic materials, is considered as the most common causative agent of occupational asthma and accounts for 9-15\% of cases in adults (3-6). The clinical manifestations and pathological changes of TDI-induced asthma are similar to those of allergic asthma; however, the pathogenesis of TDI-induced asthma still remains obscure (7). In an animal model of TDI-induced asthma, chronic airway inflammation and bronchial hyperreactivity were observed, along with the overexpression of inflammatory cytokines (8). These conditions were found to be associated with the airway submucosal 
infiltration of neutrophils, lymphocytes and eosinophils (8). In addition, previous studies have suggested that animals with asthma exhibit elevated concentrations of interleukin (IL)-4, -5 , and -13 in the bronchoalveolar lavage fluid (BALF), lung and serum (9-11).

High mobility group box 1 (HMGB1) is a classic inflammatory cytokine that is overexpressed in the lungs of asthmatic animals (12). HMGB1 is a highly conserved nuclear protein that is secreted by immune cell lineages following the stimulation of inflammatory cytokines such as tumor necrosis factor- $\alpha$ and IL-1 (13). IL-1 functions upstream of HMGB1 (14) however, there are no relevant reports regarding the mechanisms through which IL-1 can stimulate the secretion of HMGB1. In mammals, HMGB1 serves a pivotal role in mediating inflammation, and is strongly associated with the pathological processes of sepsis, pneumonia, arthritis and other diseases $(13,15)$.

Airway eosinophilia and related inflammatory cytokines contribute substantially to the airway hyperresponsiveness of asthma $(1,16)$. In this process, the typical pathological alterations in airway remodeling include the hyperplasia of goblet cells and myofibroblasts, and deposition of collagen, which is secondary to airway inflammation in the pathology of asthma (17). As a marker for fibroblasts and a factor involved in the differentiation of epithelial cells into myofibroblasts, the expression levels of $\alpha$-smooth muscle actin ( $\alpha$-SMA) indicate the formation of subepithelial fibrosis (18). In past decades, $\alpha$-SMA was reported to be an important biomarker of airway remodeling in asthma (19) by indicating the deposition of collagen I. Furthermore, overexpression of fibroblastic collagen I and $\alpha$-SMA have been reported to further aggravate airway remodeling (20).

MK2206 is an allosteric small-molecule inhibitor of AKT and exhibits promising clinical potential in the treatment of solid tumors $(21,22)$. AKT is an archetypal family member of the Ser/Thr protein kinases and downstream effector of the PI3K signaling pathway (23). Our previous study reported the importance of PI3K in asthma (24). The AKT signaling pathway is activated by phosphorylation of AKT, which subsequently activates downstream inflammatory cytokines to regulate airway smooth muscle (ASM) and inflammatory cells (23). Studies have observed that the structure and function of ASM change in patients with asthma and animal models $(25,26)$. However, the potential role of MK2206 in airway inflammation or remodeling as a result of asthma is still unclear.

Our previous study reported that the pathological changes of asthma in a TDI-induced animal model closely resemble the acute stage of human TDI asthma (27). Using this model, the effect of the AKT inhibitor, MK2206, on airway inflammation, airway remodeling and airway hyperresponsiveness (AHR) triggered by TDI-induced asthma, and the possible mechanisms were investigated. The results of the present study indicated the potential application of AKT inhibitors in the treatment of occupational asthma.

\section{Materials and methods}

Animals and drugs. A total of 24 male BALB/C mice (6-8 weeks old, $20 \pm 2 \mathrm{~g}$ ) were purchased from the Experimental
Animal Center of Southern Medical University. Mice were housed in a specific pathogen-free environment at a constant temperature of $23 \pm 1^{\circ} \mathrm{C}$ and $55 \pm 5 \%$ humidity, and provided with standard laboratory diet and drinking water ad libitum in a 12-h dark/light cycle. All mice were fed irradiated food and given access to sterile water. The study protocol for animals was approved by Southern Medical University Experimental Animal Ethics Committee (approval no. L2017177).

TDI ( $\geq 98.0 \%$ ), methacholine and acetone (all Sigma-Aldrich; Merck $\mathrm{KGaA}$ ) were administered to mice to establish TDI-induced asthma models. A 2:3 mixture of acetone and olive oil (AOO) was used to dissolve TDI, and was also used as the vehicle treatment for the study control group. For airway challenge, a 1:4 mixture of AOO was used.

Models and groups. All mice were separated into four groups randomly (n=6/group): i) Acetone and olive oil (AOO); ii) TDI; iii) TDI + MK2206; and iv) TDI + dexamethasone (DEX). Mice in the control AOO group were treated using the same procedure as the TDI asthma model group (except for the use of TDI). In this control group (AOO), mice were sensitized with $\mathrm{AOO}$ on the dorsa of both ears dermally (20 $\mu \mathrm{l} / \mathrm{ear}$ applied topically) on day 1 and day 8 . They received an injection of saline $24 \mathrm{~h}$ prior to challenge. On days 15,18 and 21 , the mice were raised in horizontal cylindrical niches individually and challenged using air with AOO. The TDI group was established according to our previously published studies $(24,28)$. On days 1 and 8 , mice were sensitized using TDI $(0.3 \%)$ on the dorsa of both ears dermally ( $20 \mu \mathrm{l} /$ ear). Then, the mice were managed in horizontal cylindrical niches individually and challenged using air with TDI (3\%) that was dissolved in a 1:4 mixture of AOO with a compressed air nebulizer (NE-C28; Omron) for $3 \mathrm{~h}$ on days 15,18 and 21. Saline was injected intraperitoneally $24 \mathrm{~h}$ before the TDI challenge, which acted as a vehicle control for the MK2206 and DEX treatments. In the TDI + MK2206 group, mice were treated using the same procedure as that for the TDI group; however, they were treated with $100 \mathrm{mg} / \mathrm{kg}$ MK2206 in saline using oral gavage $24 \mathrm{~h}$ before the air challenge. Mice in the TDI + DEX group were treated using the same procedure as that for the TDI group; they were injected with $200 \mathrm{mg} / \mathrm{kg}$ DEX in saline $24 \mathrm{~h}$ before the air challenge. All animals were sacrificed using cervical dislocation under anesthesia $(60 \mathrm{mg} / \mathrm{kg}$ intraperitoneal pentobarbital sodium) at the end of the study. The total duration of the study was less than 4 weeks and lung tissues were collected after animal sacrifice.

Immunohistochemistry. The lung tissues were fixed in $10 \%$ formalin at room temperature for $24 \mathrm{~h}$, and embedded in paraffin. Sections of the samples were deparaffinized and submerged into citrate buffer for antigen retrieval ( $\mathrm{pH}$ 6.0). To block endogenous peroxidase activity, each section $(2.5-\mu \mathrm{m}$ thick) was incubated with $0.3 \% \mathrm{H}_{2} \mathrm{O}_{2}$ at room temperature for $10 \mathrm{~min}$. After blocking in 5\% bovine serum albumin (Beijing ZSGB-BIO Technology, Ltd.) for $20 \mathrm{~min}$ at room temperature, the sections were incubated with primary antibody either rabbit anti- $\alpha$-SMA (1:100; cat. no. 23081-1-AP; Proteintech Group, Inc.) or rabbit anti-phosphorylated-AKT (p-AKT; 1:100; cat. no. 66444-1-Ig; Proteintech Group, Inc.) antibodies overnight at $4^{\circ} \mathrm{C}$. The next day, sections were washed 
three times using PBS, then incubated with biotin-conjugated anti-rabbit IgG (1:100; cat. no. BM2004; Wuhan Boster Biological Technology, Ltd.) secondary antibody for $20 \mathrm{~min}$ at room temperature. Lastly, the sections were incubated with HRP-streptavidin (1:1,000; cat. no. BIR701-3; Beijing Borsi Technology Co., Ltd.) at room temperature for $10 \mathrm{~min}$, then visualized using a DAB peroxidase kit (1:20; cat. no. AR1000; Wuhan Boster Biological Technology, Ltd.) at room temperature for $1 \mathrm{~min}$, then counterstained with hematoxylin at room temperature for $3 \mathrm{~min}$. Each stained sections were examined in at least five random visual fields using an Olympus BX53 light microscope (Olympus Corporation; magnification, x200).

Western blotting $(W B)$. Total protein from each lung tissue was extracted from the cells via lysis with RIPA lysis buffer (Beyotime Institute of Biotechnology). The protein content of the lysate was determined using a bicinchoninic acid assay kit (Beyotime Institute of Biotechnology) according to the manufacturer's protocol. Protein samples (40 ng protein/sample) were resolved using 10\% SDS-PAGE; the separated proteins were transferred onto polyvinylidene difluoride (PVDF) membranes. Next, the blots were blocked with 5\% BSA in TBS-0.05\% Tween-20 (TBST) at room temperature for $1 \mathrm{~h}$, and incubated with antibodies against AKT (1:1,000; cat. no. 10176-2-AP), p-AKT (1:1,000; cat. no. 66444-1-Ig), $\alpha$-SMA (1:1,000; cat. no. 23081-1-AP), HMGB1 (1:1,000; cat. no. 66525-1-Ig), collagen I (1:1,000; cat. no. 66761-1-Ig) and GAPDH (1:1,000; cat. no. 60004-1-Ig) all purchased from ProteinTech Group, Inc. overnight at $4^{\circ} \mathrm{C}$. The membranes were washed three times with TBST and incubated with biotin-conjugated goat anti-mouse IgG secondary antibody (1:1,000; cat. no. SA00004-1; ProteinTech Group, Inc.) or biotin-conjugated donkey anti-rabbit IgG (1:1,000; cat. no. SA00004-11; ProteinTech Group, Inc.). After incubating with HRP-streptavidin (1:5,000; BIR701-3; Beijing Borsi Technology Co., Ltd.) at room temperature for $30 \mathrm{~min}$, the blots were visualized using ECL reagent $(100 \mu 1$ per membrane; cat. no. ab133406; Abcam) with a Tanon 5200 Automatic chemiluminescence imaging analysis system (Tanon Science and Technology Co., Ltd.). The gray value of the blots were quantified by ImageJ software $(1.48 \mathrm{v}$; National Institutes of Health).

Measurement of bronchoalveolar lavage fluids. BALF was collected and centrifuged at $1,000 \mathrm{x}$ g for $10 \mathrm{~min}$ at $4^{\circ} \mathrm{C}$. The recovered lavage solution was centrifuged at room temperature at $162 \mathrm{x} \mathrm{g}$ for $10 \mathrm{~min}$ The total cell number in the BALF of each mouse was counted manually by direct microscopic counting using an Olympus BX53 light microscope (Olympus Corporation; magnification, $\mathrm{x} 400$ ). The supernatant was collected and stored at $-80^{\circ} \mathrm{C}$ for multiplex immunoassay analyses of IL-4, -5, -6 and -13 (cat. no. EK0405; EK0408; EK0411; EK0425; Wuhan Boster Biological Technology, Ltd.) in accordance with the manufacturer's protocols. The cell pellet was resuspended in $50 \mu \mathrm{l}$ saline, and the total number of cells was counted. The cells were then smeared rapidly and uniformly, and allowed to dry naturally. The slides were then fixed with $4 \%$ paraformaldehyde for $30 \mathrm{~min}$, then stained with hematoxylin and eosin (H\&E; Beijing Solarbio Science $\&$ Technology Co., Ltd.). The slides were examined using an Olympus BX53 light microscope (Olympus Corporation; magnification, $\mathrm{x} 400$ ).

Hematoxylin and eosin. The left lung was fixed with $4 \%$ paraformaldehyde for $24 \mathrm{~h}$, then dehydrated with gradient alcohol. Tissues were then incubated in with xylene for $15 \mathrm{~min}$ and embedded with paraffin. Tissue was sectioned to a thickness of $4 \mu \mathrm{m}$, and individual sections were allowed to adhere on slides and dried naturally. The slides were then incubated at $60^{\circ} \mathrm{C}$ overnight, dewaxed, stained with hematoxylin for $1 \mathrm{~min}$, and rinsed with tap water for several seconds to remove excess dye. The cells were acidified with $0.5 \%$ hydrochloric acid alcohol (prepared with 70\% ethanol) for 2-5 sec until the nuclei were blue and the cytoplasm was almost colorless. The slides were then stained with $1 \%$ eosin for $30 \mathrm{sec}$, then rinsed with running water. The slides were then dehydrated with an ascending ethanol gradient, treated with xylene and sealed with neutral gum. The infiltration of inflammatory cells in bronchial mucosa and perivascular were examined (magnification, $\mathrm{x} 200$ for lung tissue or $\mathrm{x} 400$ for cells in the BALF) under an Olympus BX53 light microscope (Olympus Corporation). The experiment was carried out at room temperature, unless otherwise specified.

Serum IgE measurements. Blood samples from the retro-orbital venous sinus were collected immediately after the mice were sacrificed by decapitation following anesthesia with intraperitoneal injection of $50 \mathrm{mg} / \mathrm{kg}$ pentobarbital, and stored at room temperature for $1 \mathrm{~h}$. The supernatants were harvested and stored at $-80^{\circ} \mathrm{C}$ after centrifugation at $3,000 \mathrm{x} \mathrm{g}$ for $10 \mathrm{~min}$ at $37^{\circ} \mathrm{C}$. Serum $\mathrm{IgE}$ levels were measured using an IgE ELISA kit (cat. no. ASB-OKIA00100; NeoBioscience Technology Co., Ltd.) according to the manufacturer's protocol.

Assessment of AHR. On day 22 of model establishment, mice were placed in a barometric plethysmographic chamber (Data Sciences International; Harvard Bioscience, Inc.) and challenged by increasing gradient concentrations of methacholine $(3.12,6.25,12.5,25$ or $50 \mathrm{mg} / \mathrm{ml})$ using ultrasonic nebulization. The aerosols were prepared using an ultrasonic nebulizer (Data Sciences International; Harvard Bioscience, Inc.) and nebulized into the chamber for $3 \mathrm{~min}$. After each atomization, the pressure fluctuations caused due to the breathing of mice were monitored for $3 \mathrm{~min}$ and then quantified using the enhanced pause algorithm (Penh, dimensionless parameter), which represented the precise resistance index for airway recovery $(29,30)$.

Histological measurements in lungs. The left lungs of mice were harvested and fixed in $4 \%$ paraformaldehyde at room temperature for $24 \mathrm{~h}$. After dehydration and paraffin embedding, coated glass slides with $4-\mu \mathrm{m}$ sections were stained with H\&E. Blinded histological assessment was performed as previously described (31). Briefly, peribronchial and perivascular inflammation was measured by using the following scoring standard: $0=$ normal; $1=$ infrequent inflammatory cells; $2=$ a ring of inflammatory cells 1 cell-layer deep; $3=a$ ring of inflammatory cells $2-4$ cells deep; and $4=$ a ring of inflammatory cells $>4$ cells deep. The histological scores and average epithelial reticular basement membrane thickness 
(measured manually) were calculated using an Olympus BX53 light microscope (Olympus Corporation; agnification, x200) and at least 40 fields of 20 sections from each mouse were recorded.

To quantify goblet cell numbers in the epithelium, the paraffin-embedded samples were cut into $5-6-\mu \mathrm{m}$ sections and stained with periodic acid-Schiff (PAS) at room temperature for $10 \mathrm{~min}$. The results of PAS staining were assessed in at least five random fields under an Olympus BX53 light microscope (Olympus Corporation; magnification, x200). The hyperplasia goblet cells were quantified as previously described (32). The pathological changes were classified using a modified five-point scoring system (grades 0-4) based on the percentage of goblet cells in the epithelium: Grade 0 (no goblet cells); grade $1(<25 \%)$; grade $2(25-50 \%)$; grade $3(51-75 \%)$; and grade $4(>75 \%)$. The mean scores of the 6 mice in each group were calculated.

Immunofluorescence measurements. The 16HBE cell line (American Type Culture Collection) was cultured with RPMI-1640 containing 10\% FBS (both from Gibco; Thermo Fisher Scientific, Inc.) in a cell-culture incubator at $37^{\circ} \mathrm{C}$ with $5 \% \mathrm{CO}_{2}$. At $90 \%$ confluence, cells were placed on a coverslip in six-well plates at a density of $2 \times 10^{5}$ cells/well. MK2206 $(1 \mu \mathrm{g} / \mathrm{ml})$ or DEX $(1 \mu \mathrm{g} / \mathrm{ml})$ was added to the medium $1 \mathrm{~h}$ before TDI $(60 \mu \mathrm{g} / \mathrm{ml})$ exposure for $6 \mathrm{~h}$. For immunocytochemistry, cells were fixed in $4 \%$ formaldehyde-PBS at room temperature for $10 \mathrm{~min}$, permeabilized in $0.5 \%$ Triton X-100 at room temperature for $5 \mathrm{~min}$ and blocked with $5 \%(\mathrm{w} / \mathrm{v}) \mathrm{BSA}$ for $1 \mathrm{~h}$ at room temperature, followed by overnight incubation with anti- $\alpha$-SMA (1:100; cat. no. 23081-1-AP; ProteinTech Group, Inc.) and anti-HMGB1 (1:100; cat. no. 66525-1-Ig; ProteinTech Group, Inc.) antibodies at $4^{\circ} \mathrm{C}$. The next day, cells were washed in three times PBS and incubated with Alexa Fluor ${ }^{\circledR}$ 488-labeled goat anti-mouse IgG antibody (1:1,000; cat. no. SA00004-11; ProteinTech Group, Inc.) at room temperature for $1 \mathrm{~h}$ in the dark. The nuclei were stained with DAPI (Beyotime Institute of Biotechnology) at room temperature for $10 \mathrm{~min}$. The immunofluorescence of $\alpha$-SMA and HMGB1 was observed at $\mathrm{x} 200$ magnification using a laser-scanning confocal microscope (Olympus Corporation). The immunofluorescence was quantified by ImageJ software (1.48v; National Institutes of Health).

Statistical analysis. Data were presented as the mean \pm SEM of three experiments. One-way ANOVA followed by Bonferroni post hoc testing was performed to compare differences between multiple groups for continuous data; Kruskal-Wallis test followed by Dunn's multiple comparison test was used for ordinal data. All statistical analyses were conducted using SPSS 13.0 (SPSS, Inc.) or GraphPad Prism 8 (GraphPad Software, Inc.) for continuous or ordinal data, respectively. $\mathrm{P}<0.05$ was considered to indicate a statistically significant difference.

\section{Results}

MK2206 inhibits AKT, $p$-AKT, collagen I, $\alpha$-SMA and HMGB1 in lung tissue. The expression levels of collagen I, $\alpha$-SMA, HMGB1 and p-AKT were significantly upregulated in the TDI group compared with those in the AOO group ( $\mathrm{P}<0.05$; Fig. 1A-B). In addition, compared with the TDIgroup, the expression levels of collagen I, $\alpha$-SMA, HMGB1 and p-AKT in the TDI + MK2206 and TDI + DEX groups were significantly decreased ( $\mathrm{P}<0.05$; Fig. 1A-B).

MK2206 reduces AHR. In the present study, airway reactivity was measured at $24 \mathrm{~h}$ after an air challenge. With an increase in methacholine concentration, the Penh value of airway reactivity demonstrated an upward trend in all groups. The airway reactivity was significantly increased in the TDI group compared with the AOO, TDI + MK2206 and TDI + DEX groups $(\mathrm{P}<0.05$; Fig. 2$)$. In addition, no significant differences were observed between the airway responsiveness of the AOO, TDI + MK2206 and TDI + DEX groups $(\mathrm{P}>0.05$; Fig. 2).

MK2206 reduces airway inflammation. To assess the effect of MK2206 on TDI-induced allergic airway inflammation, the levels of cytokines in BALF and total serum IgE were determined. The results demonstrated that the levels of IL-4, $-5,-6$ and -13 , and serum IgE were significantly increased in the TDI group compared with those of the AOO group $(\mathrm{P}<0.05$; Fig. 3A and B). In addition, the TDI + MK2206 and TDI + DEX groups demonstrated significantly lower levels of IL-4, $-5,-6$ and-13, and serum IgE compared with those of the TDI group ( $\mathrm{P}<0.05$; Fig. $3 \mathrm{~A}$ and $\mathrm{B}$ ).

Total cell counts and percentages of different immune cells were assessed in the BALF. The results demonstrated that the number of neutrophils and eosinophils were significantly higher in the TDI group compared with those of the AOO group $(\mathrm{P}<0.05$; Fig. $4 \mathrm{~A}$ and $\mathrm{B})$. This finding suggested that TDI triggered inflammatory responses. Conversely, compared with the AOO group, the number of macrophages in the TDI group was significantly reduced $(\mathrm{P}<0.05$; Fig. 4B). In addition, the number of neutrophils and eosinophils in the TDI + MK2206 and TDI + DEX groups were significantly lower compared with those of the TDI group ( $\mathrm{P}<0.05$; Fig. $4 \mathrm{~A}$ and $\mathrm{B})$, but no significant differences were observed in the lymphocyte and macrophage count (Fig. 4A and B). Additionally, the total cell count in the BALF was significantly increased in the TDI group compared to that of AOO group ( $\mathrm{P}<0.05$; Fig. 4C), whereas that of the TDI + MK2206 was significantly lower compared to that of the TDI group $(\mathrm{P}<0.05$; Fig. $4 \mathrm{C})$. These results suggested that MK2206 and DEX served protective roles in airway inflammation.

In the AOO group, bronchial, alveolar and vascular structures appeared normal and intact; the infiltration of inflammatory cells around the bronchial wall was not observed and the bronchial epithelial cells were not proliferated or shed (Fig. 4A). In contrast, in the TDI group, the airway epithelium started to shed, epithelial cell proliferation and mucous secretion increased, and numerous neutrophils, eosinophils and lymphocytes infiltrated the tube wall (Fig. 4A). In addition, compared with the TDI group, the inflammation scores of the TDI + MK2206 and TDI + DEX groups were significantly decreased $(\mathrm{P}<0.05$; Fig. $4 \mathrm{D})$, manifestation of inflammation appeared to be slightly attenuated and airway epithelial hyperplastic differentiation was weakened (Fig. 4B-D). 
A
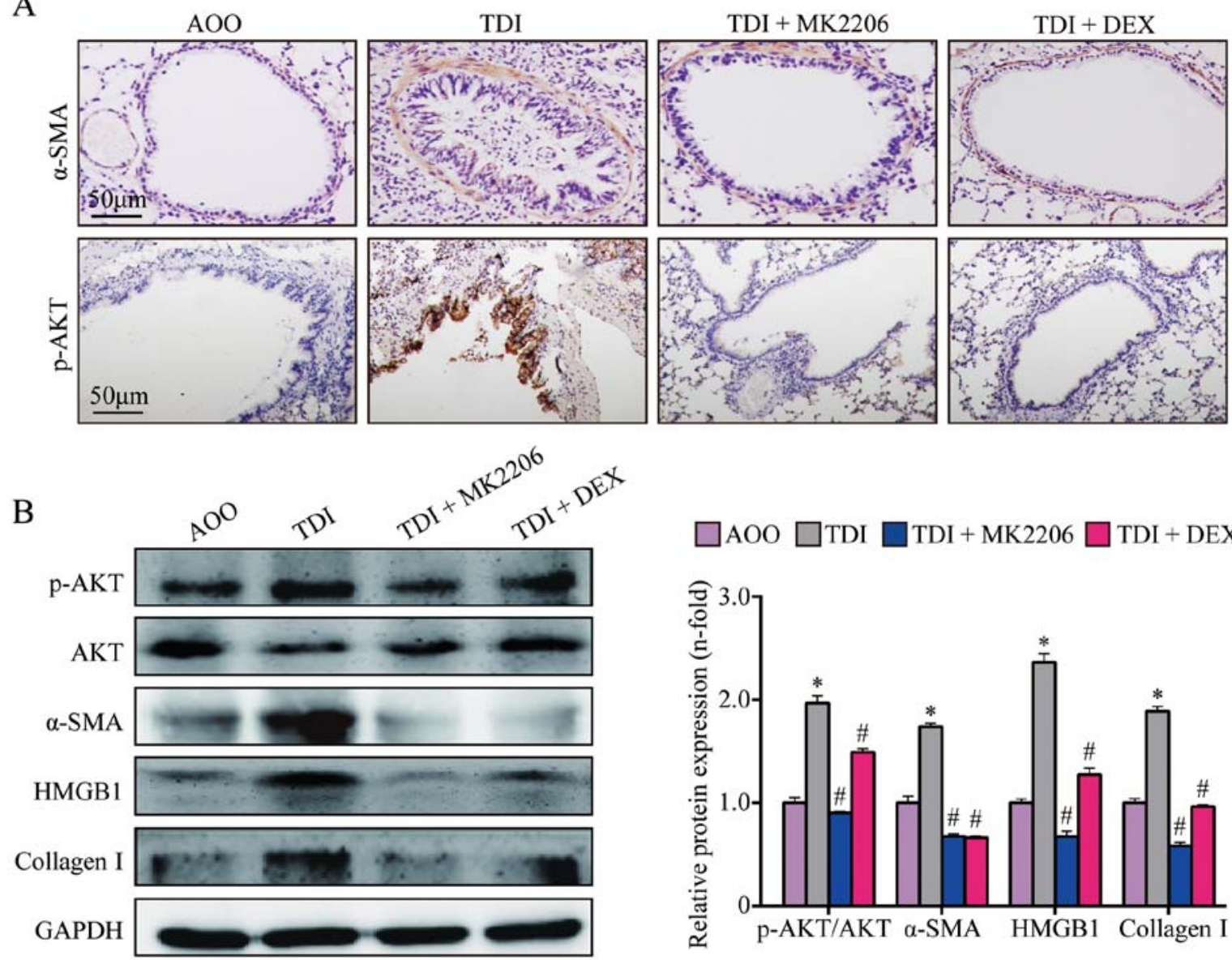

$\square$ AOO $\square$ TDI $\square$ TDI + MK2206 $\square$ TDI + DEX

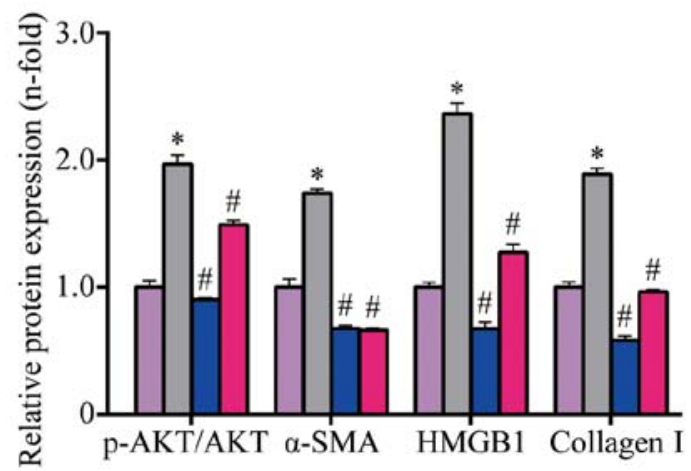

Figure 1. Effect of MK2206 on AKT phosphorylation in lung tissue. (A) Immunohistochemistry analysis of p-AKT and $\alpha$-SMA among four groups. (B) Western blot analysis of lung tissue from four groups, and data analysis of the blots. Data are presented as the mean $\pm \mathrm{SEM}$ ( $\mathrm{n}=6 /$ group). ${ }^{*} \mathrm{P}<0.05$ vs. AOO group; ${ }^{*} \mathrm{P}<0.05$ vs. TDI group. p-AKT, phosphorylated-AKT; $\alpha$-SMA, $\alpha$-smooth muscle actin; TDI, toluene diisocyanate; AOO, acetone and olive oil; DEX, dexamethasone; HMGB1, high mobility group box 1 .

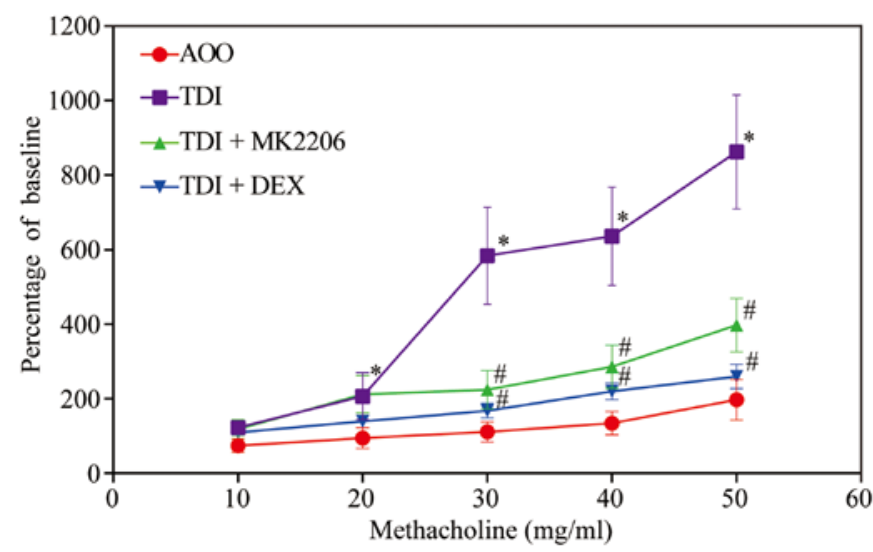

Figure 2. Effects of MK2206 on TDI-induced AHR. AHR to methacholine was measured $24 \mathrm{~h}$ after the last TDI challenge. Data are presented as the mean \pm SEM ( $n=6 /$ group). ${ }^{*} \mathrm{P}<0.05$ vs. AOO group; ${ }^{\#} \mathrm{P}<0.05$ vs. TDI group. AHR, airway hyperresponsiveness; TDI, toluene diisocyanate; AOO, acetone and olive oil; DEX, dexamethasone.

MK2206 inhibits airway remodeling. PAS staining demonstrated that goblet cells occupied the largest proportion of cells in the TDI group, compared with the AOO group.
The proportion of goblet cells was reduced following MK2206 and DEX treatment (Fig. 5A). In addition, the PAS score and basement membrane thickness in the TDI group were significantly increased compared with the AOO group $(\mathrm{P}<0.05$; Fig. 5B and $\mathrm{C})$. Conversely, the PAS scores and basement membrane thickness in the TDI + MK2206 and TDI + DEX groups were significantly decreased compared with those of the TDI group $(\mathrm{P}<0.05$; Fig. 5B and C).

MK2206 suppresses AKT activation in TDI-treated $16 H B E$ cells. Results from in vitro studies demonstrated that AKT was activated, and the expression of $\alpha$-SMA and HMGB1 was upregulated in $16 \mathrm{HBE}$ cells after TDI stimulation $(\mathrm{P}<0.05$; Fig. 6A and B). In addition, the results from WB demonstrated that the activation of AKT was inhibited, and the expression of $\alpha$-SMA and HMGB1 was downregulated by MK2206 $(\mathrm{P}<0.05$; Fig. 6C). In order to further elucidate the redistribution of $\alpha$-SMA and HMGB1 in 16HBE cells, the distribution of $\alpha$-SMA and HMGB1 were examined and quantified. Confocal microscopy demonstrated different distributions of $\alpha$-SMA and HMGB1 between the TDI group and the other groups, and increased $\alpha$-SMA and HMGB1 translocation into the 
A

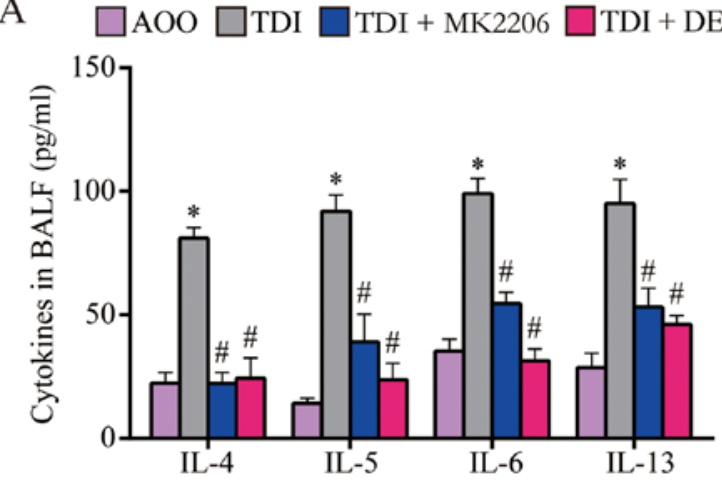

B

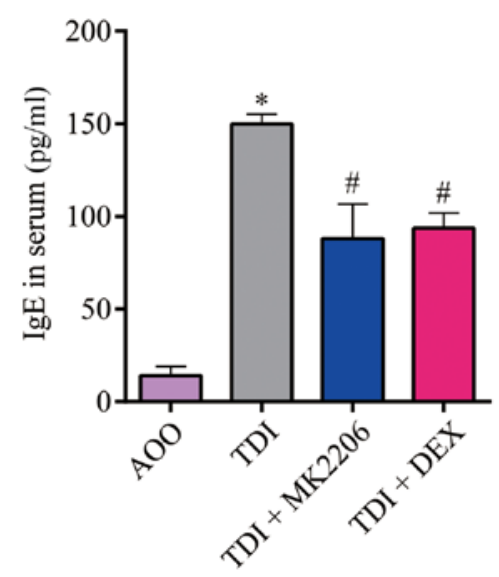

Figure 3. Effects of MK2206 on the cytokines in BALF and total serum IgE following TDI-induced airway inflammation. (A) Cytokines in bronchoalveolar lavage fluid were measured using ELISA. (B) Serum total IgE was measured using ELISA. Data are presented as the mean \pm SEM ( $n=6 /$ group). ${ }^{*} \mathrm{P}<0.05 \mathrm{vs}$. AOO group; ${ }^{\#} \mathrm{P}<0.05$ vs. TDI group. BALF, bronchoalveolar lavage fluid; TDI, toluene diisocyanate; AOO, acetone and olive oil; DEX, dexamethasone.

A

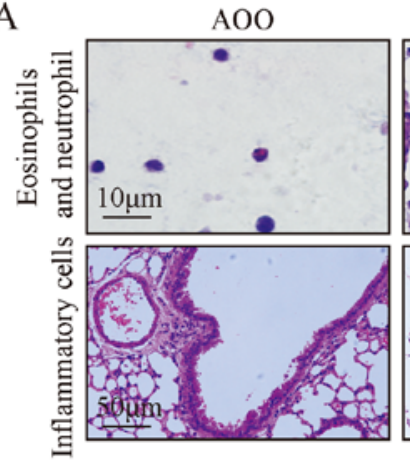

$\mathrm{B}$

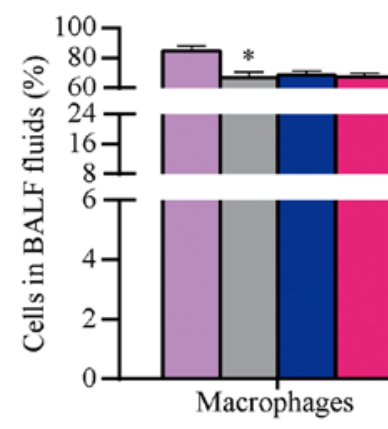

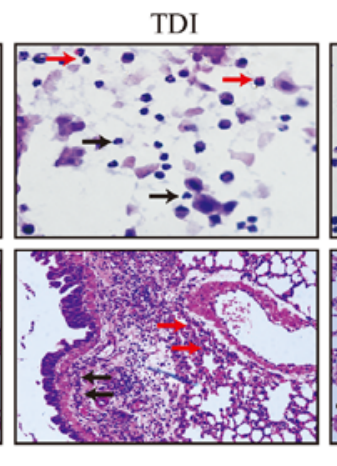
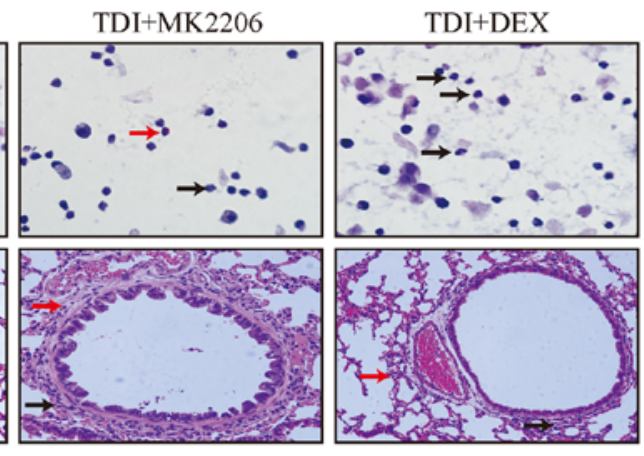

$\square$ AOO $\square$ TDI $\square$ TDI+MK2206 $\square$ TDI+DEX
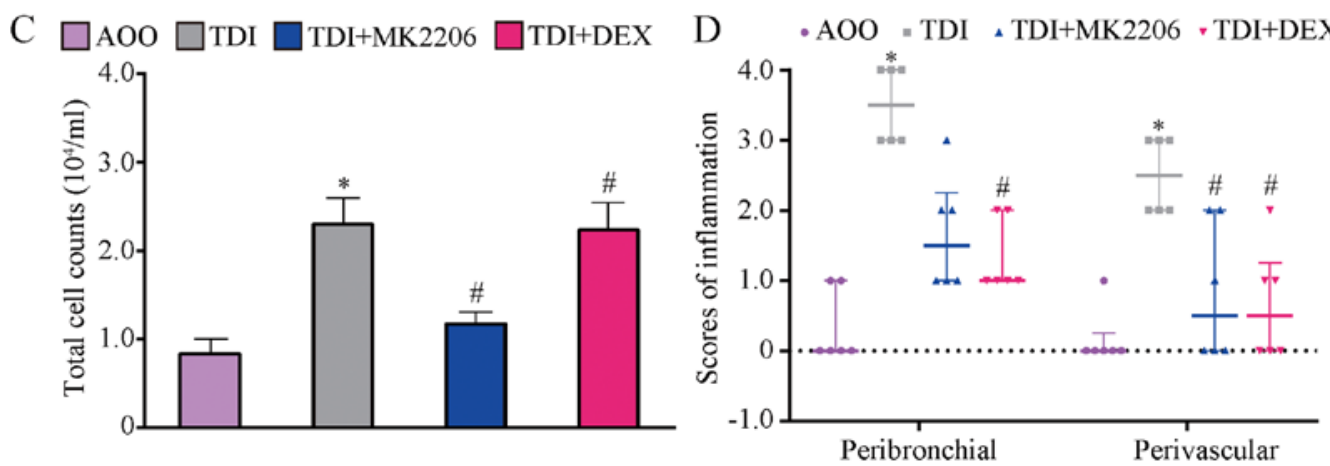

Figure 4. Effects of MK2206 on TDI-induced inflammatory infiltration in BALF and pulmonary histological changes. (A) Hematoxylin and eosin staining of cell smears of BALF at x400 magnification (upper panel). Red arrows indicate eosinophils; black arrows indicate neutrophils. Hematoxylin and eosin staining of lung tissue at x200 magnification (lower panel). Red arrows indicate inflammatory cell infiltration around vessels; black arrows indicate inflammatory cell infiltration around the airways (bronchia). (B) Macrophages, neutrophils, eosinophils and lymphocytes in BALF. (C) Total inflammatory cell counts in BALF. (D) Results of histological scoring for peribronchial inflammatory changes and perivascular inflammatory changes of lung sections from different groups. Data are presented as the mean \pm SEM (n=6/group). ${ }^{*} \mathrm{P}<0.05$ vs. AOO group; ${ }^{*} \mathrm{P}<0.05$ vs. TDI group. BALF, bronchoalveolar lavage fluid; TDI, toluene diisocyanate; AOO, acetone and olive oil; DEX, dexamethasone. 
A

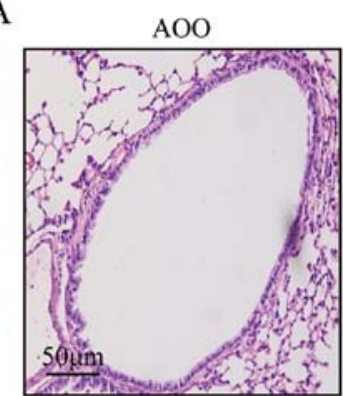

B

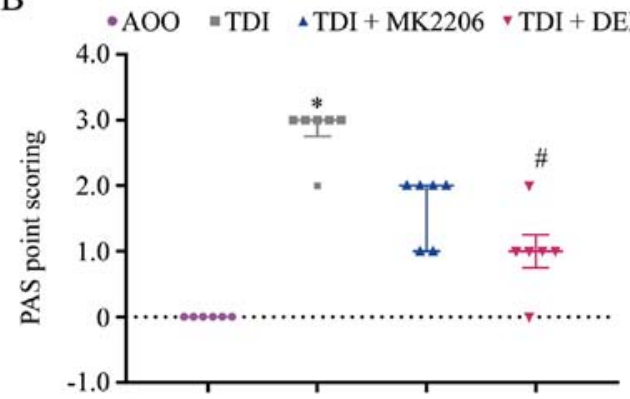

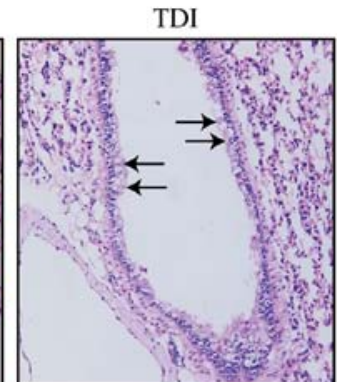
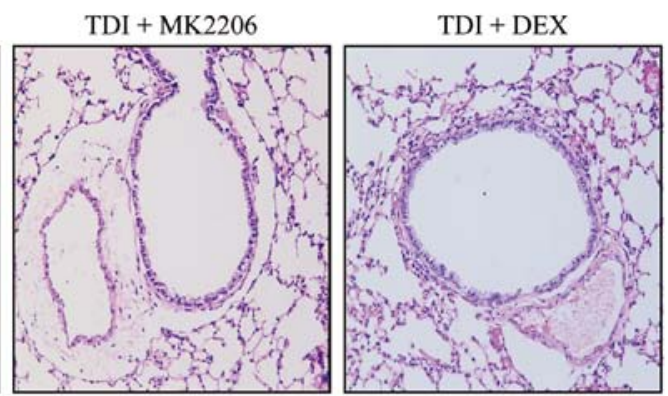

$\mathrm{C}$

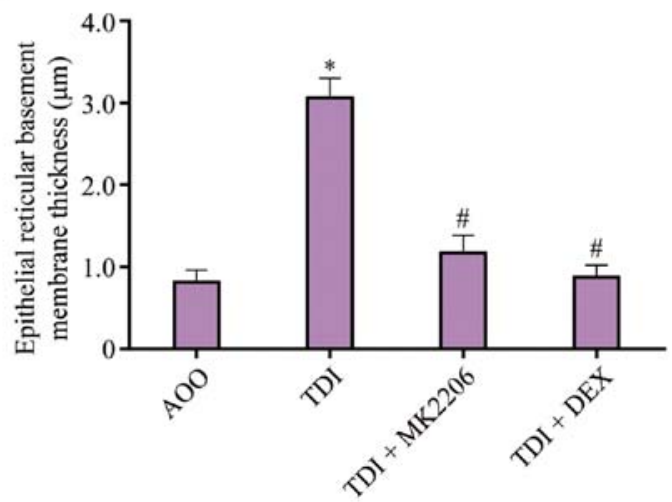

Figure 5. Effects of MK2206 on goblet cell hyperplasia in lung tissue. (A) Paraffin-embedded tissue sections stained with PAS. (B) Goblet cell hyperplasia quantification based on the percentage of goblet cells in the epithelium. (C) Quantification of average epithelial reticular basement membrane thickness measurement. Data are presented as the mean \pm SEM ( $n=6$ /group). ${ }^{*} \mathrm{P}<0.05$ vs. AOO group; ${ }^{\#} \mathrm{P}<0.05$ vs. TDI group. TDI, toluene diisocyanate; AOO, acetone and olive oil; DEX, dexamethasone; PAS, periodic acid-Schiff.

cytosol in the TDI group, compared with all other groups $(\mathrm{P}<0.05$; Fig. 7A-C). These data suggested that AKT phosphorylation inhibition may serve a crucial role in TDI-induced redistribution of $\alpha$-SMA and HMGB1.

\section{Discussion}

Although asthma can be currently managed by attenuating the symptoms in most cases, $5-10 \%$ of patients still suffer from severe asthma and cannot be treated effectively (33). Severe asthma displays a high rate of morbidity and mortality, and has been reported to be responsible for $50 \%$ of all asthma-related treatment costs $(34,35)$. Activation of AKT can accelerate tumorigenesis and suppress tumor invasion in transgenic mouse models $(36,37)$. Clinical studies mainly focus on the inhibition of AKT by MK2206 in cancer; for example, a phase II study revealed that MK2206 + erlotinib is an effective combination in advanced non-small cell lung cancer (38). However, the effect of MK2206 in asthma remains unclear. The present study aimed to find alternative treatments with fewer side effects in the management of asthma. The results of the present study suggested that MK2206 may attenuate airway inflammation and remodeling induced by TDI treatment by inhibiting AKT phosphorylation. These findings suggested that MK2206 may be a potential drug candidate for the treatment of asthma.

In the present study, an airway challenge with TDI significantly elevated the levels of p-AKT and induced airway inflammation. This inflammation was indicated by the upregulation of inflammatory cytokines in the BALF, increased serum IgE levels and elevated numbers of inflammatory cells. DEX was used as a positive control to evaluate the role of MK2206 in the TDI mouse model of asthma. Glucocorticoids, as the cornerstone of the treatment of asthma disease, serve an important role in inhibiting airway inflammation in asthma (35). In the TDI asthma model, glucocorticoids can not only inhibit airway inflammation, but also protect airway barrier function (39). However, glucocorticoids may increase the risks of severe systemic diseases such as osteoporosis, diabetes and obesity $(8,40)$. Notably, the results of the present study demonstrated that TDI treatment resulted in airway remodeling of the lung as indicated by goblet cell hyperplasia; it also increased the production of $\alpha$-SMA and collagen I. However, the levels of airway inflammation and remodeling were significantly inhibited after MK2206 administration. MK2206 displayed similar inhibitory effects on AKT phosphorylation, airway inflammation and airway remodeling as DEX, a well-known drug recommended for the treatment of severe asthma (39).

TDI exposure resulted in the infiltration of airway inflammatory cells. Enhanced production of the inflammatory factors IL-4, -5 and -13 was observed in asthma and also found to be expressed abnormally in the TDI-induced asthma mouse model (21). The activation of T cells is mediated by IL-4, and IL-13 is associated with increased airway mucous secretion and bronchial hyperresponsiveness $(41,42)$. IL-13 expression enhances smooth muscle strength, and results in airway hyperresponsiveness (25) independent of $\mathrm{T}$ and $\mathrm{B}$ cells (26). Additionally, IL-6, as a pivotal regulator of inflammation, is elevated in the airways consistently in 
A

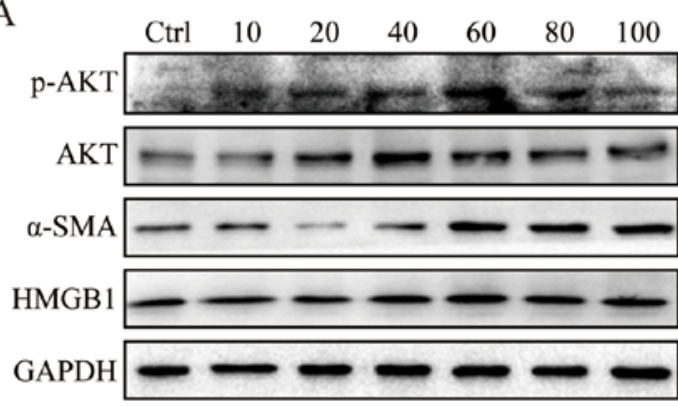

B
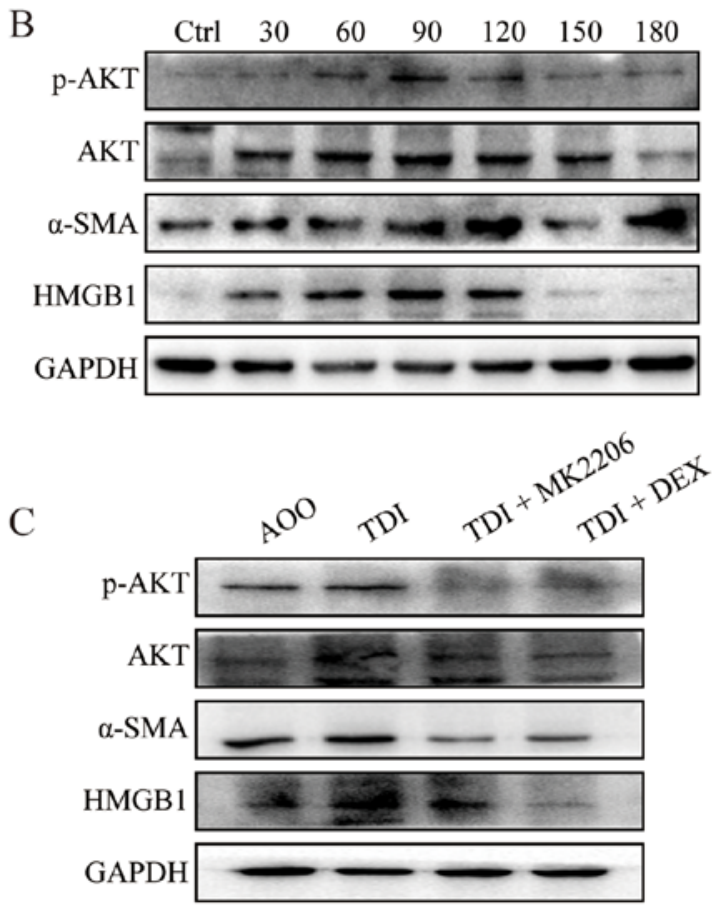
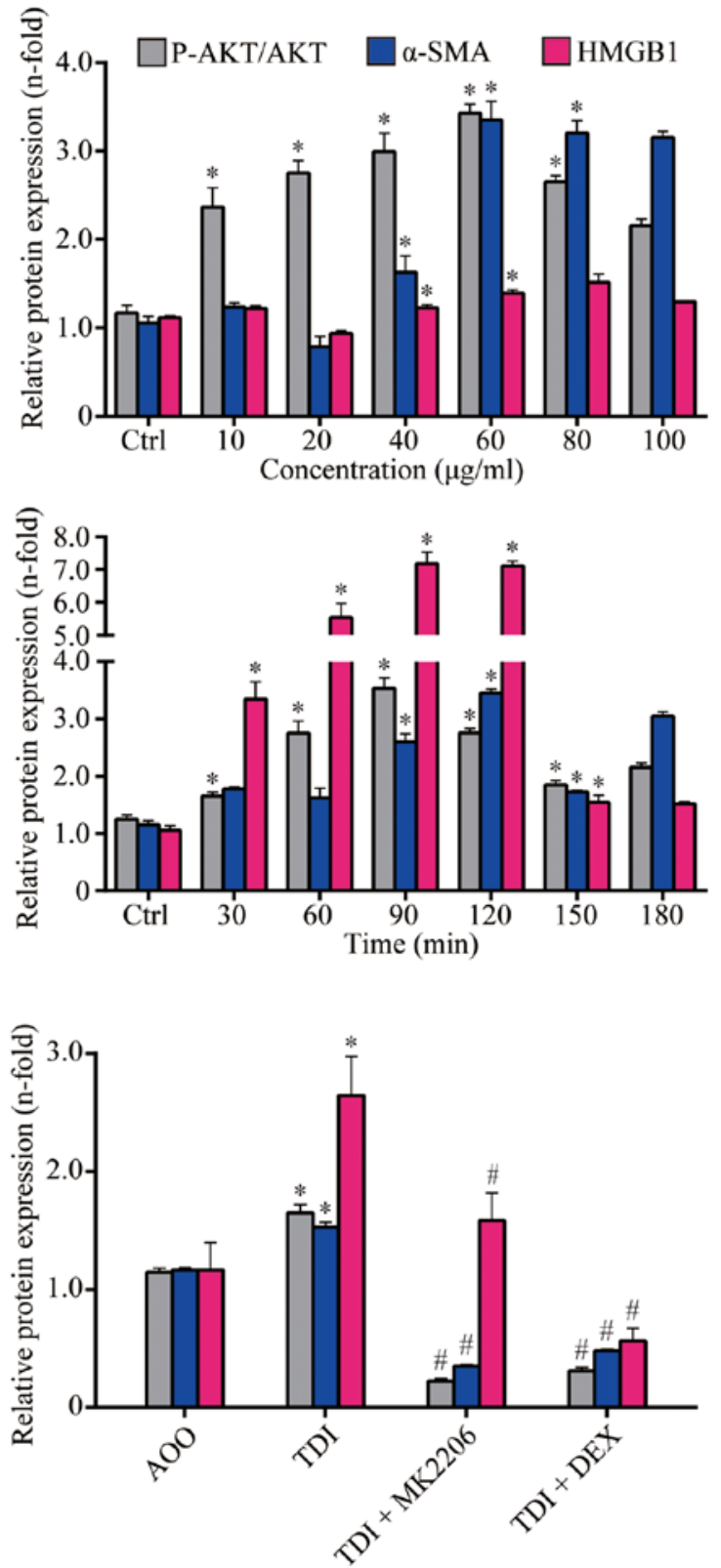

Figure 6. MK2206 suppresses AKT activation in TDI-treated 16HBE cells. (A) TDI induced the activation of the AKT. 16HBE cells were exposed to different concentration of TDI (20-100 $\mu \mathrm{g} / \mathrm{ml})$ for $30 \mathrm{~min} .{ }^{*} \mathrm{P}<0.05 \mathrm{vs}$. Ctrl group. (B) Time course of TDI-induced AKT activation. Cells were stimulated with $60 \mu \mathrm{g} / \mathrm{ml}$ TDI for the indicated times. (C) Effect of MK2206 on AKT activation induced by TDI. Cells were stimulated with $60 \mu \mathrm{g} / \mathrm{ml}$ TDI for $90 \mathrm{~min}$ after treatment with $1 \mu \mathrm{g} / \mathrm{ml}$ MK2206 or $1 \mu \mathrm{g} / \mathrm{ml}$ DEX for $1 \mathrm{~h}$. Data are presented as the mean $\pm \mathrm{SEM}$ (n=6/group). ${ }^{*} \mathrm{P}<0.05$ vs. AOO group; ${ }^{*} \mathrm{P}<0.05$ vs. TDI group. TDI, toluene diisocyanate; AOO, acetone and olive oil; DEX, dexamethasone; p-AKT, phosphorylated AKT; $\alpha$-SMA, $\alpha$-smooth muscle actin; HMGB1, high mobility group box 1 .

children and adults with asthma. Additionally, IL-6 levels are considered to be an indicator of forced expiratory volume in $1 \mathrm{sec}$ and forced vital capacity $(24,27)$. Consistent with previous studies $(4,23,28)$, the results of the present study indicated that $\mathrm{p}$-AKT was found to be significantly elevated in the TDI group, which demonstrated its involvement in airway inflammation.

MK2206 inhibits the autophosphorylation of AKT and phosphorylation of downstream signals that mediate airway inflammation by regulating further granulocyte recruitment (28). Thus, the inhibition of AKT phosphorylation is one of the important steps in the signaling pathway involved in the immune response, which regulates the transcription activity of pro-inflammatory cytokine genes such as IL-4 and IL-13 (43). Tang et al (44) reported that AKT activation increases IL-6 expression in human lung epithelial cells, and AKT and AKT phosphorylation are both decreased after small interfering RNA treatment. Consistent with previous reports, the results of the present study demonstrated that MK2206 inhibited the phosphorylation of AKT and production of cytokines (IL-4, -5, -6 and -13) in a mouse model of TDI-induced asthma. In addition, the present study also revealed that MK2206 inhibited the phosphorylation of AKT in vitro. These results indicated a potential role for MK2206 in a clinical setting for the management of TDI-induced asthma. 
A
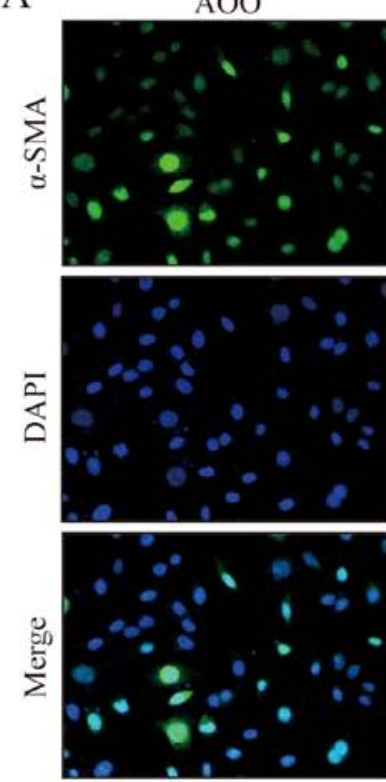

B
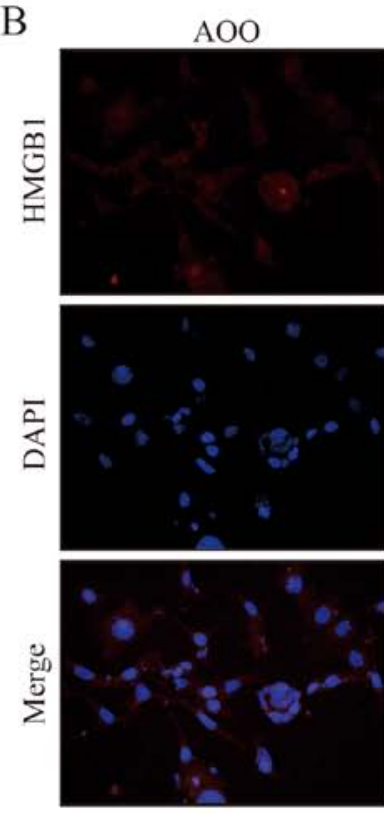

C
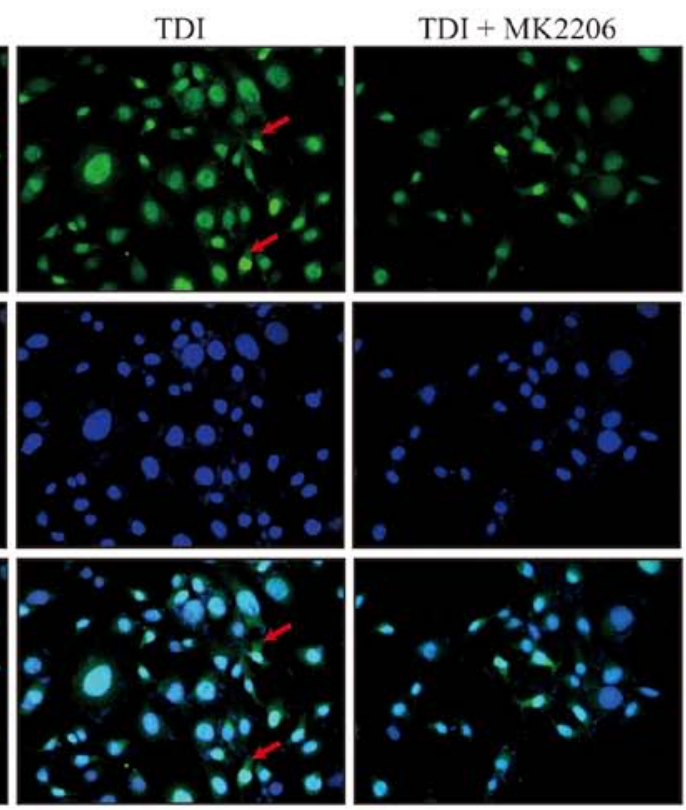

TDI
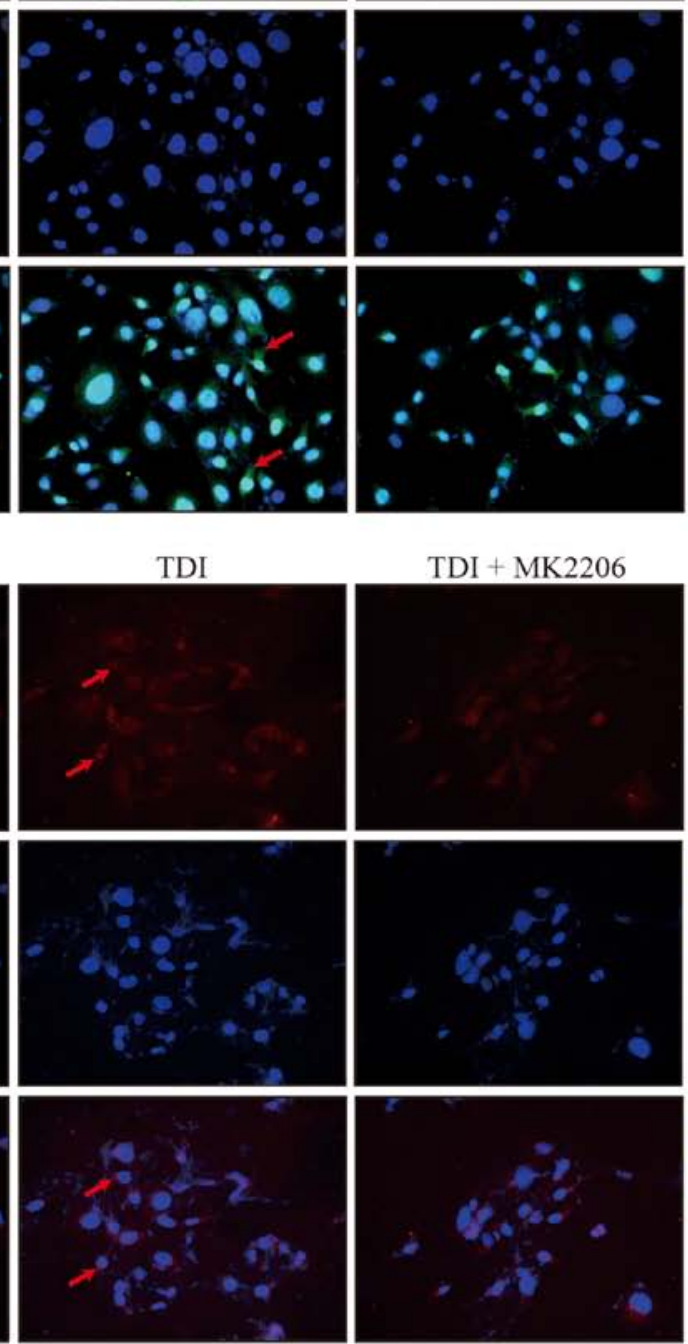

TDI + MK2206
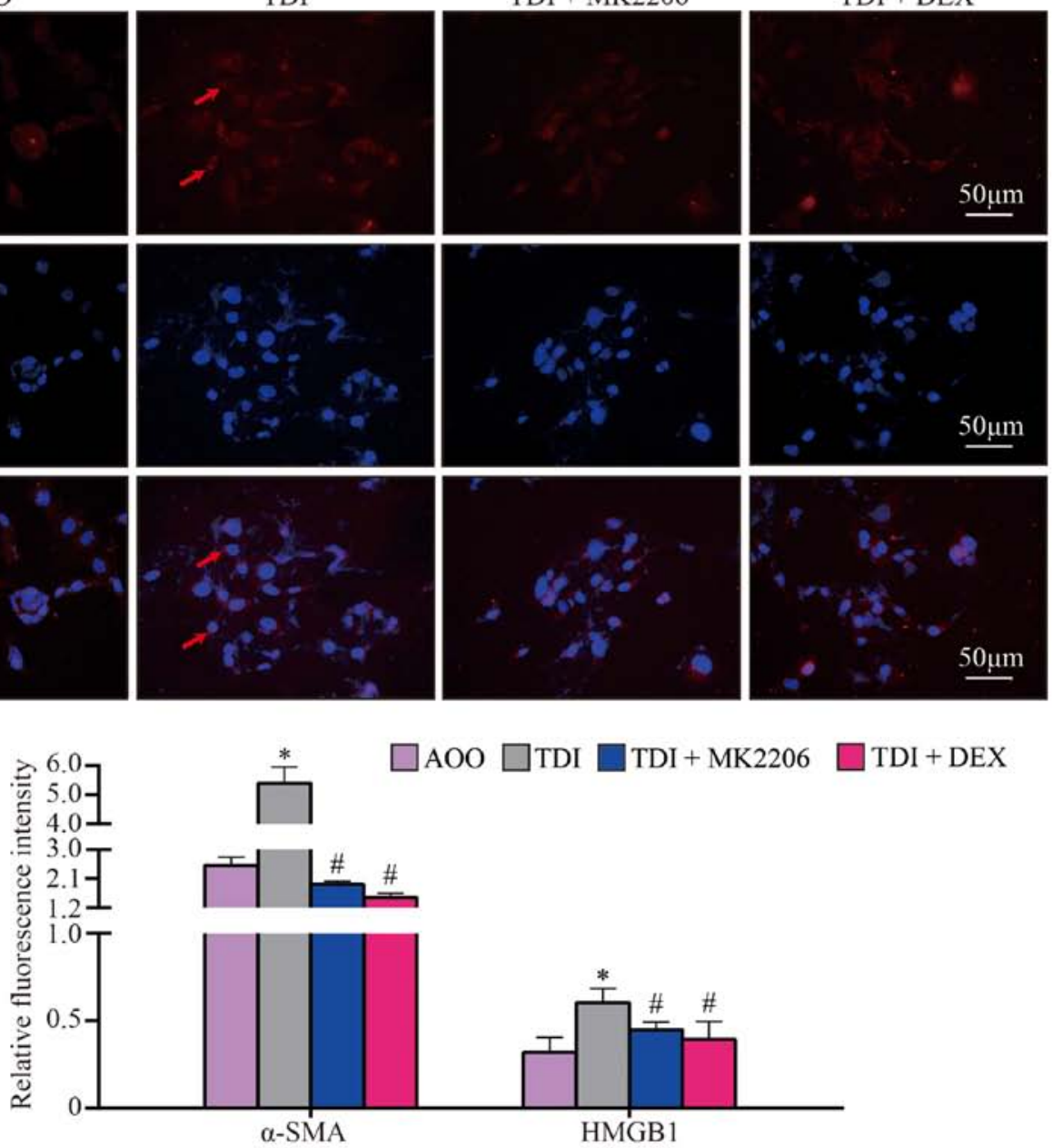

$\mathrm{TDI}+\mathrm{DEX}$
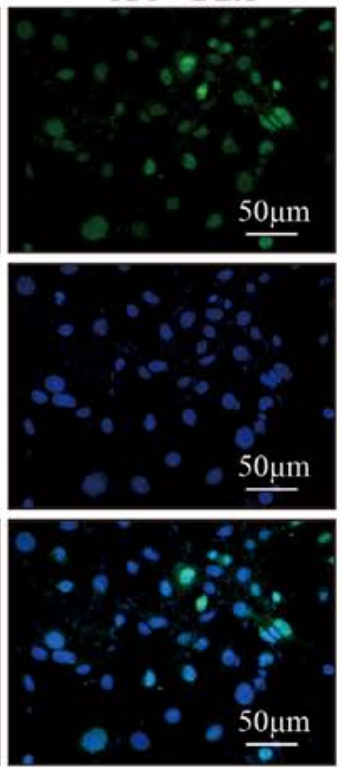

$\mathrm{TDI}+\mathrm{DEX}$
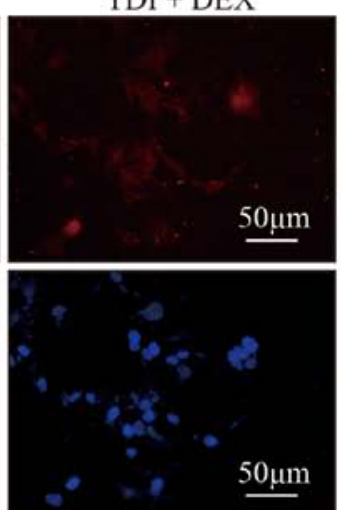

$\mathrm{TDI}+\mathrm{DEX}$

Figure 7. TDI-induced redistribution of $\alpha$-SMA and HMGB1 in 16HBE cells. MK2206 and DEX attenuated redistribution of (A) $\alpha$-SMA and (B) HMGB1, as analyzed via immunofluorescence and $(\mathrm{C})$ quantified. ${ }^{*} \mathrm{P}<0.05$ vs. AOO group; ${ }^{\#} \mathrm{P}<0.05$ vs. TDI group. TDI, toluene diisocyanate; AOO, acetone and olive oil; DEX, dexamethasone; $\alpha$-SMA, $\alpha$-smooth muscle actin; HMGB1, high mobility group box 1.

AHR is reported in individuals with bronchial remodeling and asthma (45); reduced AHR is an important indicator of therapeutic benefit. The present study indicated that MK2206 decreased AHR by controlling bronchial remodeling. In a classic inflammatory microenvironment, activated fibroblasts differentiate into myofibroblasts, and 


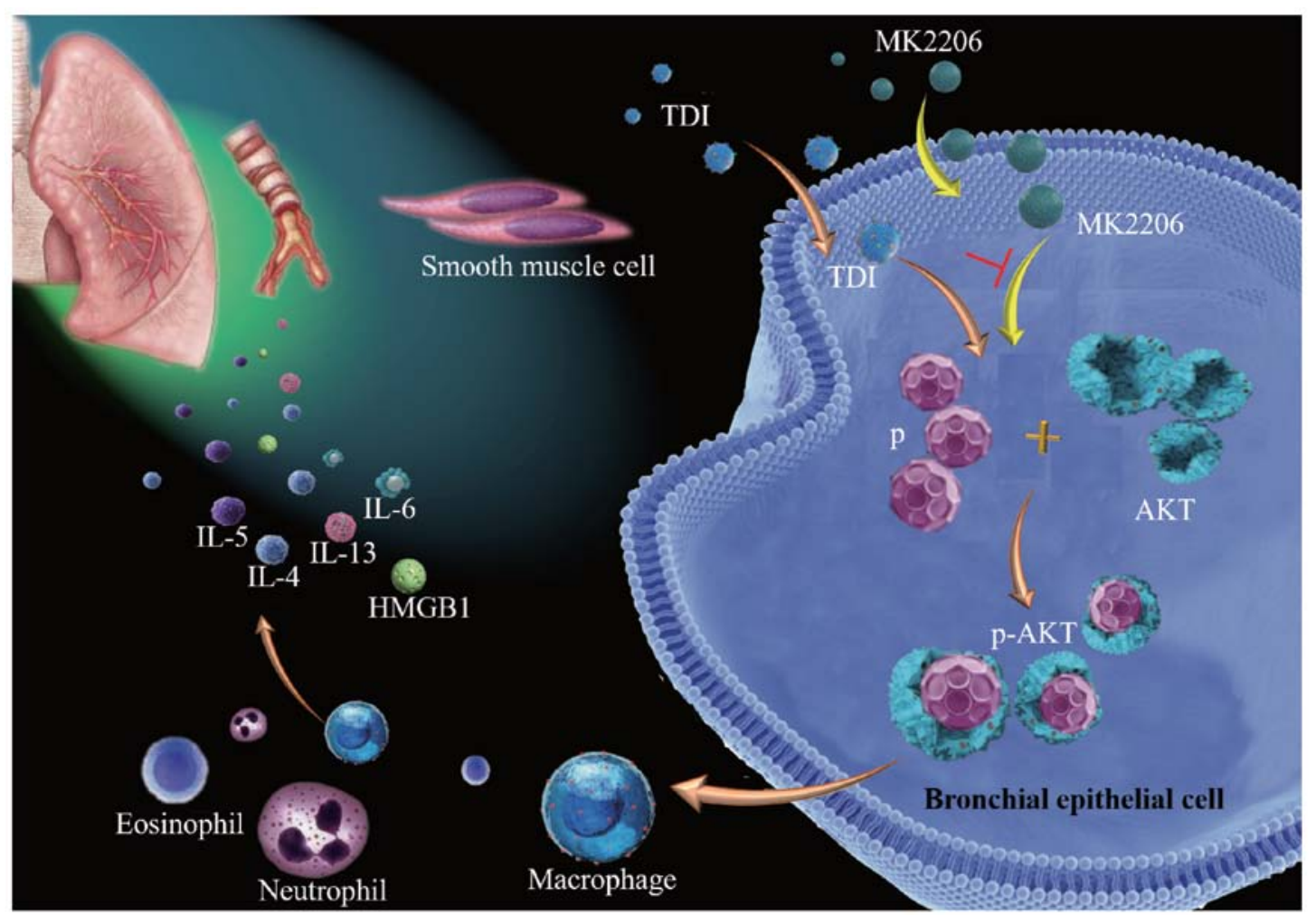

Figure 8. Mechanism of MK2206 inhibiting activation of AKT in TDI-induced asthma. In bronchial epithelial cells, MK2206 suppresses the activation of AKT, which results in the inhibition of neutrophils, eosinophil infiltration, the expression of inflammatory mediators (IL-4, -5, -6 and -13 , HMGB1), and the production of $\alpha$-smooth muscle actin and collagen I. TDI, toluene diisocyanate; HMGB1, high mobility group box 1; p-AKT, phosphorylated AKT; p, phosphate; IL, interleukin.

release pro-inflammatory factors and extracellular matrix proteins to increase airway remodeling $(46,47)$. The production of $\alpha$-SMA is indicative of myofibroblast formation and collagen I deposition (48). Myofibroblasts are proposed to be the primary effectors of lung fibrotic responses, which are characterized by the expression of $\alpha$-SMA stress fibers (48). The results of the present study demonstrated that the number of goblet cells and expression levels of $\alpha$-SMA were greater in the asthma group compared with those in the AOO and TDI + MK2206 groups. These findings provided new experimental evidence supporting the potential use of MK2206 as a new therapeutic drug for the treatment of TDI-induced asthma.

Clinical studies and experiments using animal models have demonstrated an important role of HMGB1 and its receptors in airway inflammation and asthma $(12,49)$. MK2206 is a known antitumor agent that exerts its effect by inhibiting p-AKT activation (50). The present study demonstrated that MK2206 inhibited the expression of HMGB1 in vitro and in vivo. Tumor growth factor- $\beta$ increases AKT phosphorylation (22), and MK2206 may have some effects on this signaling pathway while reducing airway inflammation.

The present study demonstrated that the inhibition of AKT activation using MK2206 attenuated AHR, airway inflammation, and airway remodeling in a TDI-induced mouse model of asthma (Fig. 8). These findings enriched current knowledge regarding MK2206 and provided the basis for future investigation. However, the current study has several limitations; for example, the role of AKT signaling in asthma, and the specific mechanism of HMGB1 in TDI-induced asthma and AKT activation were not fully investigated.

In summary, the present study demonstrated that MK2206 may serve a role in reversing airway inflammation and airway remodeling in chemical-induced asthma. These findings may therefore provide the basis for future development of MK2206 in the treatment of occupational asthma.

\section{Acknowledgements}

Not applicable.

\section{Funding}

This work was supported by the National Natural Science Foundation of China (grant no. 81770033), a National Health and Medical Research Council grant (grant no. 1158402), the Scientific and Technological Project of Guangdong Province (grant no. 2017B020226006), the National Key Research and Development Plan of China (grant no. 2016YFC0905800), and the Science and Technology Program of Guangzhou (grant no. 201804010069).

\section{Availability of data and materials}

The datasets used and/or analyzed during the current study are available from the corresponding author on reasonable request. 


\section{Authors' contributions}

SC and JD conceived and designed the experiments. HC, YC, YH, WC, WZ and HZ performed the experiments. HC, YC, LW, FHZ and JD analyzed and interpreted the data. HC, LW, JD, SC and FHZ drafted this manuscript. HC, SC, LW, FHZ and JD revised the manuscript. All authors read and approved the final manuscript.

\section{Ethics approval and consent to participate}

This study was approved by the Southern Medical University Experimental Animal Ethics Committee (approval no. L2017177).

\section{Patient consent for publication}

Not applicable.

\section{Competing interests}

The authors declare that they have no competing interests.

\section{References}

1. Berend N, Salome CM and King GG: Mechanisms of airway hyperresponsiveness in asthma. Respirology 13: 624-631, 2008.

2. Chapman KR, Albers FC, Chipps B, Muñoz X, Devouassoux G Bergna M, Galkin D, Azmi J, Mouneimne D, Price RG and Liu MC: The clinical benefit of mepolizumab replacing omalizumab in uncontrolled severe eosinophilic asthma. Allergy 74 $1716-1726,2019$

3. Balmes J, Becklake M, Blanc P, Henneberger P, Kreiss K, Mapp C, Milton D, Schwartz D, Toren K, Viegi G, et al: American Thoracic Society Statement: Occupational contribution to the burden of airway disease. Am J Respir Crit Care Med 167: 787-797, 2003.

4. Padoan M, Pozzato V, Simoni M, Zedda L, Milan G, Bononi I, Piola C, Maestrelli P, Boschetto P and Mapp CE: Long-term follow-up of toluene diisocyanate-induced asthma. Eur Respir J 21: 637-640, 2003

5. Maestrelli P, Boschetto P, Fabbri LM and Mapp CE: Mechanisms of occupational asthma. J Allergy Clin Immunol 123: 531-544, 2009.

6. Collins JJ, Anteau S, Conner PR, Cassidy LD, Doney B, Wang ML, Kurth L, Carson M, Molenaar D, Redlich CA and Storey E: Incidence of occupational asthma and exposure to toluene diisocyanate in the United States Toluene Diisocyanate Production Industry. J Occup Environ Med 59 (Suppl 12): S22-S27, 2017.

7. Mapp CE, Balboni A, Baricordi R and Fabbri LM: Human leukocyte antigen associations in occupational asthma induced by isocyanates. Am J Respir Crit Care Med 156 (Suppl): S139-S143, 1997.

8. Song J, Zhao H, Dong H, Zhang D, Zou M, Tang H, Liu L, Liang Z, Lv Y, Zou F and Cai S: Mechanism of E-cadherin redistribution in bronchial airway epithelial cells in a TDI-induced asthma model. Toxicol Lett 220: 8-14, 2013.

9. Yao L, Zhao H, Tang H, Song J, Dong H, Zou F and Cai S: Phosphatidylinositol 3-Kinase Mediates $\beta$-catenin dysfunction of airway epithelium in a toluene diisocyanate-induced murine asthma model. Toxicol Sci 147: 168-177, 2015.

10. Kwak YG, Song CH, Yi HK, Hwang PH, Kim JS, Lee KS and Lee YC: Involvement of PTEN in airway hyperresponsiveness and inflammation in bronchial asthma. J Clin Invest 111: 1083-1092, 2003.

11. Maltby S, Tay HL, Yang M and Foster PS: Mouse models of severe asthma: Understanding the mechanisms of steroid resistance, tissue remodelling and disease exacerbation. Respirology 22 874-885, 2017.
12. Hou C, Kong J, Liang Y, Huang H, Wen H, Zheng X, Wu L and Chen Y: HMGB1 contributes to allergen-induced airway remodeling in a murine model of chronic asthma by modulating airway inflammation and activating lung fibroblasts. Cell Mol Immunol 12: 409-423, 2015.

13. Musumeci D, Roviello GN and Montesarchio D: An overview on HMGB1 inhibitors as potential therapeutic agents in HMGB1-related pathologies. Pharmacol Ther 141: 347-357, 2014.

14. Ullah MA, Loh Z, Gan WJ,Zhang V, Yang H, Li JH, Yamamoto Y, Schmidt AM, Armour CL and Hughes JM: Receptor for advanced glycation end products and its ligand high-mobility group box-1 mediate allergic airway sensitization and airway inflammation. J Allergy Clin Immunol 134: 440-450, 2014.

15. Yang Q, Liu X, Yao Z, Mao S, Wei Q and Chang Y: Penehyclidine hydrochloride inhibits the release of high-mobility group box 1 in lipopolysaccharide-activated RAW264.7 cells and cecal ligation and puncture-induced septic mice. J Surg Res 186: 310-317, 2014.

16. Cockcroft DW and Davis BE: Mechanisms of airway hyperresponsiveness. J Allergy Clin Immunol 118: 551-561, 2006.

17. Warner SM and Knight DA: Airway modeling and remodeling in the pathogenesis of asthma. Curr Opin Allergy Clin Immunol 8: 44-48, 2008.

18. Valatas V, Filidou E, Drygiannakis I and Kolios G: Stromal and immune cells in gut fibrosis: The myofibroblast and the scarface. Ann Gastroenterol 30: 393-404, 2017.

19. Davies DE, Wicks J, Powell RM, Puddicombe SM and Holgate ST: Airway remodeling in asthma: New insights. J Allergy Clin Immunol 111: 215-226, 2003.

20. Cao L, Liu F, Liu Y, Liu T, Wu J, Zhao J, Wang J, Li S, Xu J and Dong L: TSLP promotes asthmatic airway remodeling via p38-STAT3 signaling pathway in human lung fibroblast. Exp Lung Res 44: 288-301, 2018.

21. Somnay Y, Simon K, Harrison AD, Kunnimalaiyaan S, Chen H and Kunnimalaiyaan M: Neuroendocrine phenotype alteration and growth suppression through apoptosis by MK-2206, an allosteric inhibitor of AKT, in carcinoid cell lines in vitro. Anticancer Drugs 24: 66-72, 2013.

22. Yahiro Y, Maeda S, Shinohara N, Jokoji G, Sakuma D, Setoguchi T, Ishidou Y, Nagano S, Komiya S and Taniguchi N: PEG10 counteracts signaling pathways of TGF- $\beta$ and BMP to regulate growth, motility and invasion of SW1353 chondrosarcoma cells. J Bone Miner Metab 37: 441-454, 2019.

23. Yang N, Zhang H, Cai X and Shang Y: Epigallocatechin-3-gallate inhibits inflammation and epithelial-mesenchymal transition through the PI3K/AKT pathway via upregulation of PTEN in asthma. Int J Med 41: 818-828, 2018.

24. Liang J, Zhao H, Yao L, Tang H, Dong H, Wu Y, Liu L, Zou F and Cai S: Phosphatidylinositol 3-kinases pathway mediates lung caspase-1 activation and high mobility group box 1 production in a toluene-diisocyanate induced murine asthma model. Toxicol Lett 236: 25-33, 2015 .

25. Lezmi G, Gosset P, Deschildre A, Abou-Taam R, Mahut B, Beydon $\mathrm{N}$ and de Blic $\mathrm{J}$ : Airway remodeling in preschool children with severe recurrent wheeze. Am J Respir Crit Care Med 192: 164-171, 2015

26. Wen X, Yan J, Han XR, Zheng GH, Tang R, Liu LF, Wu DM, $\mathrm{Lu} J$ and Zheng YL: PTEN gene silencing contributes to airway remodeling and induces airway smooth muscle cell proliferation in mice with allergic asthma. J Thoracic Dis 10: 202-211, 2018.

27. Xiong J, Zhao W, Lin Y, Yao L, Huang G, Yu C, Dong H, Xiao G, Zhao H and Cai S: Phosphorylation of low density lipoprotein receptor-related protein 6 is involved in receptor for advanced glycation end product-mediated $\beta$-catenin stabilization in a toluene diisocyanate-induced asthma model. Int Immunopharmacol 59: 187-196, 2018.

28. Yao L, Zhao H, Tang H, Liang J, Liu L, Dong H, Zou F and Cai S: The receptor for advanced glycation end products is required for beta-catenin stabilization in a chemical-induced asthma model. Br J Pharmacol 173: 2600-2613, 2016.

29. Lundblad LK, Irvin CG, Adler A and Bates JH: A reevaluation of the validity of unrestrained plethysmography in mice. J Appl Physiol 93: 1198-1207, 2002.

30. Ye Z, Huang Y, Liu D, Chen X, Wang D, Huang D, Zhao L and Xiao X: Obesity induced by neonatal overfeeding worsens airway hyperresponsiveness and inflammation. PLoS One 7: e47013, 2012 
31. Tang H, Zhao H, Song J, Dong H, Yao L, Liang Z, LV Y, Zou F and Cai S: Ethyl pyruvate decreases airway neutrophil infiltration partly through a high mobility group box 1-dependent mechanism in a chemical-induced murine asthma model. Int Immunopharmacol 21: 163-170, 2014.

32. Padrid P, Snook S, Finucane T, Shiue P, Cozzi P, Solway J and Leff AR: Persistent airway hyperresponsiveness and histologic alterations after chronic antigen challenge in cats. Am J Respir Crit Care Med 151: 184-193, 1995.

33. Chung KF, Wenzel SE, Brozek JL, Bush A, Castro M, Sterk PJ, Adcock IM, Bateman ED, Bel EH, Bleecker ER, et al: International ERS/ATS guidelines on definition, evaluation and treatment of severe asthma. Eur Respir J 43: 343-373, 2014.

34. Soriano JB, Abajobir AA, Abate KH, Abera SF, Agrawal A, Ahmed MB, Aichour AN, Aichour I, Aichour MTE, Alam K, et al: Global, regional, and national deaths, prevalence, disability-adjusted life years, and years lived with disability for chronic obstructive pulmonary disease and asthma, 1990-2015: A systematic analysis for the Global Burden of Disease Study 2015. Lancet Respir Med 5: 691-706, 2017.

35. Al Efraij K and FitzGerald JM: Current and emerging treatments for severe asthma. J Thorac Dis 7: E522-E525, 2015.

36. Hutchinson JN, Jin J, Cardiff RD, Woodgett JR and Muller WJ: Activation of Akt-1 (PKB-alpha) can accelerate ErbB-2-mediated mammary tumorigenesis but suppresses tumor invasion. Cancer Res 64: 3171-3178, 2004.

37. Chin YR and Toker A: Akt isoform-specific signaling in breast cancer: Uncovering an anti-migratory role for palladin. Cell Adh Migr 5: 211-214, 2011

38. Lara PN Jr,Longmate J, Mack PC, Kelly K, Socinski MA, Salgia R, Gitlitz B, Li T, Koczywas M, Reckamp KL and Gandara DR: Phase II study of the AKT Inhibitor MK-2206 plus Erlotinib in patients with advanced non-small cell lung cancer who previously progressed on erlotinib. Clin Cancer Res 21: 4321-4326, 2015.

39. Brooks SM, Werk EE, Ackerman SJ, Sullivan I and Thrasher K: Adverse effects of phenobarbital on corticosteroid metabolism in patients with bronchial asthma. N Engl J Med 286: 1125-1128, 1972.

40. Mylka V, Deckers J, Ratman D, De Cauwer L, Thommis J, De Rycke R, Impens F, Libert C, Tavernier J, Vanden Berghe W, et al: The autophagy receptor SQSTM1/p62 mediates anti-inflammatory actions of the selective NR3C1/glucocorticoid receptor modulator compound $\mathrm{A}(\mathrm{Cpd} \mathrm{A})$ in macrophages. Autophagy 14: 2049-2064, 2018.
41. Takeda M, Ito W, Tanabe M, Ueki S, Kihara J, Kato H, Tanigai T, Kayaba H, Sasaki T and Chihara J: The pathophysiological roles of PI3Ks and therapeutic potential of selective inhibitors in allergic inflammation. Int Arch Allergy Immunol 152 (Suppl 1): S90-S95, 2010

42. Kampe M, Lampinen M, Stolt I, Janson C, Stalenheim G and Carlson M: PI3-kinase regulates eosinophil and neutrophil degranulation in patients with allergic rhinitis and allergic asthma irrespective of allergen challenge model. Inflammation 35 : 230-239, 2012.

43. Chung MJ, Sohng JK, Choi DJ and Park YI: Inhibitory effect of phloretin and biochanin A on IgE-mediated allergic responses in rat basophilic leukemia RBL-2H3 cells. Life Sci 93: 401-408, 2013

44. Tang L, Chen Q, Meng Z, Sun L, Zhu L, Liu J, Hu J, Ni Z and Wang X: Suppression of Sirtuin-1 increases IL-6 expression by activation of the akt pathway during allergic asthma. Cell Physiol Biochem 43: 1950-1960, 2017.

45. Le Cras TD, Acciani TH, Mushaben EM, Kramer EL, Pastura PA, Hardie WD, Korfhagen TR, Sivaprasad U, Ericksen M, Gibson AM, et al: Epithelial EGF receptor signaling mediates airway hyperreactivity and remodeling in a mouse model of chronic asthma. Am J Physiol Lung Cell Mol Physiol 300: L414-L421, 2011.

46. Postma DS and Timens W: Remodeling in asthma and chronic obstructive pulmonary disease. Proc Am Thoracic Soc 3: 434-439, 2006

47. Halwani R, Al-Muhsen S and Hamid Q: Airway remodeling in asthma. Curr Opin Pharmacol 10: 236-245, 2010.

48. Wang N, Yan D, Liu Y, Liu Y, Gu X, Sun J, Long F and Jiang S: A HuR/TGF- $\beta 1$ feedback circuit regulates airway remodeling in airway smooth muscle cells. Respir Res 17: 117, 2016.

49. Hou C, Zhao H, Liu L, Li W, Zhou X, Lv Y, Shen X, Liang Z, Cai $S$ and Zou F: High mobility group protein B1 (HMGB1) in Asthma: Comparison of patients with chronic obstructive pulmonary disease and healthy controls. Mol Med 17: 807-815, 2011.

50. Winder A, Unno K, Yu Y, Lurain J and Kim JJ: The allosteric AKT inhibitor, MK2206, decreases tumor growth and invasion in patient derived xenografts of endometrial cancer. Cancer Biol Ther 18: 958-964, 2017.

This work is licensed under a Creative Commons

Attribution-NonCommercial-NoDerivatives 4.0 International (CC BY-NC-ND 4.0) License. 